\title{
Copolymerization of Acrylamide with Acrylic acid
}

\author{
Mahmoud A. Al-Issa*
}

Ameen H. Mohammed*

Received 1, March, 2011

Accepted 7, June, 2011

\begin{abstract}
:
Low conversion copolymerization of acrylamide AM (monomer-1) have been conducted with acrylic acid AA in dry benzene at $70^{\circ} \mathrm{C}$, using Benzoyl peroxide BPO as initiator. The copolymer composition has been determined by elemental analysis. The monomer reactivity ratios have been calculated by the Kelen-Tudos and FinmanRoss graphical procedures. The derived reactivity ratios $\left(r_{1}, r_{2}\right)$ are: $(0.620,0.996)$ for (AM / AA) systems, and found that the reactivity of the monomer AA is more than the monomer AM in the copolymerization of (AA/AM) system. The reactivity ratios values were used for microstructures calculation.
\end{abstract}

Key words : Acrylamide, acrylic acid, copolymerization, reactivity ratio.

\section{Introduction:}

Poly (acrylamide - Co- acrylic acid) PAM/AA is generally made by free radical polymerization [1]. It prepared successfully in aqueous salt solution using anionic polyelectrolytes as stabilizers [2]. PAM/AA resin prepared from AA and AM by inverse suspension polymerization; it used to separate transitional metal ions $\mathrm{Cu}^{+2}$, $\mathrm{Ni}^{+2}, \mathrm{Co}^{+2}[3]$. Goa and $\mathrm{Wu}$ prepare (PAM/AA) / poly(vinyl pyrrolidone ) blends by dispersion polymerization [4]. PAM/AA is important classes of water-soluble polymers due to their numerous applications in fields such as super absorbents additives in cosmetics, membrane technology, waste-water treatment and oil field operations[5]. The photolytic and photocatalytic degradation of this copolymer has been conducted in the presence of combustion-synthesized nanoanatase titania [6].

The estimation of copolymer composition and determination of reactivity ratios are significant for tailor-making properties. Copolymerization modulates both the intramolecular and intermolecular forces exercised between like and unlike polymer segments and consequently properties such as glass transition temperature, melting point, solubility, permeability, adhesion, dyeability and chemical reactivity may be varied withen a wide limits. The utility of copolymerization is exemplified on the one hand by the fundamental investigation of structure property relation [7] and on the other hand by the wide range of commercial application. The relative reactivity of a monomer toward a certain polymer radical is readily calculated from the monomer reactivity ratios of copolymerization. However, evalution of the rate constants of crosspropagating is required for estimation of the absolute reactivities of the polymer radical and of the monomer [8].

\section{Materials and Methods:}

All , monomer, initiator, and solvent have been obtained from Aldrich-Oma Chemical Co.Acrylamide was recrystillized from chloroform several time and dried under vacuum

\footnotetext{
*Department of Chemistry, college of science for Women, Baghdad Universit.
} 
until all chloroform are removed. Initiator (Benzoyl peroxide) was purified by twice recrystallizations from chloroform and refrigerated prior to use.

Copolymerization of AM with AA was carried out using $\left(1 \times 10^{-3} \mathrm{~mol} \mathrm{dm}^{-3}\right)$ $\mathrm{BPO}$ as initiator and $(8 \mathrm{ml})$ dry benzene as solvent at $70^{\circ} \mathrm{C}$ in glass tubes. The glass tubes were charged with the prescribed amount of monomers. The total molar composition of the monomer mixture was maintained at $\left(3.5 \mathrm{~mol} \mathrm{dm}^{-3}\right)$ while the feed ratio was varied. Placed in water bath at $70^{\circ} \mathrm{C}$. After the required time $(<10 \%$ conversion $)$ The copolymers were precipitated in petroleum ether (b.p. $40-60^{\circ} \mathrm{C}$ ). The precipitates were filtered off, dissolved again in benzene and precipitated in petroleum ether prior to constant weight in vacuum at $35^{\circ} \mathrm{C}$. The copolymer compositions were determined by elemental analysis.

\section{Results and Discussion:}

The reactivity ratios $r_{1}$ and $r_{2}$ of copolymerization of AM ( monomer-1) with AA has been determined using Fineman-Ross [9] and Kelen-Tudos [10] procedures . For mathematical details of these procedures, the original papers [9-10] should be consulted. The plots are show in fig. $(1,2)$ for FinemanRoss and Kelen-tudos respectively. The results of the reactivity ratios are given in table (1).

Table (1): Monomer reactivity ratios for the copolymerization of AM with AA

\begin{tabular}{|c|c|c|}
\hline Procedure & $\begin{array}{c}\mathrm{AM}(\mathrm{M}) \\
\mathbf{r}_{1}\end{array}$ & $\begin{array}{c}\mathrm{AA}(\mathrm{M}) \\
\mathbf{r}_{2}\end{array}$ \\
\hline Fineman-Ross & $\mathbf{0 . 6 1 3}$ & $\mathbf{0 . 9 7 1}$ \\
\hline Kelen-Tudos & $\mathbf{0 . 6 2 8}$ & $\mathbf{1 . 0 2 2}$ \\
\hline Avrage-values & $\mathbf{0 . 6 2 0}$ & $\mathbf{0 . 9 9 6}$ \\
\hline & $\pm \mathbf{0 . 0 0 8}$ & $\mathbf{\mathbf { 0 . 0 2 6 }}$ \\
\hline
\end{tabular}

With these values of $r_{1}$ and $r_{2}$, the variation of the instantaneous mole fraction $\mathrm{f}_{1}$ of $\mathrm{AM}$ in the initial feed may be calculated using the following copolymer composition eqn. [11]

$$
\mathrm{F}=\mathrm{r}_{1} \mathrm{f}_{1}{ }^{2}+\mathrm{f}_{1} \mathrm{f}_{2} / \mathrm{r}_{1} \mathrm{f}_{1}{ }^{2}+2 \mathrm{f}_{1} \mathrm{f}_{2}+\mathrm{r}_{2} \mathrm{f}_{2}^{2}
$$

Where $F=F_{1} / F_{2}, r_{1}=$ reactivity ratio of AA, $r_{2}=$ reactivity ratio of $\mathrm{AM}, \mathrm{f}_{1}=$ mole fraction of $\mathrm{AA}$ in the feed, $\mathrm{f}_{2}=$ mole fraction of AM in the feed.

Figure (3), shows the copolymer composition curves of AM/AA system, which shows no azotropic composition.

The azotropic feed composition $\mathrm{f}_{1}(\mathrm{az}$.$) is given by:$

$$
\mathrm{f}_{1}(\mathrm{az})=\left(1-\mathrm{r}_{1}\right) /\left(2-\mathrm{r}_{1}-\mathrm{r}_{2}\right) \text {. }
$$

$\mathrm{f}_{1}(\mathrm{az})=$ azotropic feed composition.

The cross - propagation step in copolymerization reaction in values. Addition of certain polymer radical to a monomer molecule. The corresponding rate constant kij of cross-propagation reflecting the relative reactivity of monomer-j toward a given polymer radical-I may be readily calculated from reactivity ratios $\left(\mathrm{K}_{12}=\mathrm{K}_{11} / \mathrm{r}_{1}, \mathrm{~K}_{21}=\mathrm{K}_{22} / \mathrm{r}_{2}\right)$.In absence of reliable data on the absolute rate constants of propagation of $\mathrm{AM}$ at the conditions employed here, comparisons may be made on the basis of reactivity ratios alone.

The reactivity ratios were then used for microstructural calculation. The microstructure of the copolymers was expected to be very important in determining the solution properties which the copolymer exhibit [12]. Igarashi 's [13] methods used to calculate the fraction of $\mathrm{M}_{1}-\mathrm{M}_{1}, \mathrm{M}_{2-}$ $\mathrm{M}_{2}$ and $\mathrm{M}_{1}-\mathrm{M}_{2}$ units (the mole $\%$ of blockness, the mole \% of altervation and the mean sequence length of the comonomers respectively) in the copolymers as a function of reactivity ratios.

The copolymer composition, tables (1 and 2), lists the structural data for the copolymer AM/AA . For the system of AM/AA copolymers, table 
(2) the mean sequence length of AM, $\mu_{1}$, Varied from 1.182 to 3.021. For these copolymer compositions, values of $\mu_{2}$ were 5.056 and 1.253 respectively.

Table (2): Structural data for the copolymers AA/ AM

\begin{tabular}{|c|c|c|c|}
\hline $\begin{array}{l}\text { Test } \\
\text { No. }\end{array}$ & $\begin{array}{l}\text { Blockiness } \\
(\mathrm{mol} \%)\end{array}$ & $\begin{array}{l}\text { Alternation } \\
(\mathrm{mol} \%)\end{array}$ & $\begin{array}{c}\text { Mean } \\
\text { Seqeunce } \\
\text { length }\end{array}$ \\
\hline & $\begin{array}{l}\mathrm{M}_{1}-\mathrm{M}_{1} \\
\mathrm{M}_{2}-\mathrm{M}_{2}\end{array}$ & $\mathrm{M}_{1}-\mathrm{M}_{2}$ & $\begin{array}{l}\mu_{1} \\
\mu_{2}\end{array}$ \\
\hline 1 & $\begin{array}{l}36.67 \\
26.01\end{array}$ & 37.32 & $\begin{array}{l}1.182 \\
5.056\end{array}$ \\
\hline 2 & $\begin{array}{l}34.65 \\
22.64\end{array}$ & 42.71 & $\begin{array}{l}1.435 \\
2.549\end{array}$ \\
\hline 3 & $\begin{array}{l}33.22 \\
20.95\end{array}$ & 45.83 & $\begin{array}{l}1.679 \\
2.037 \\
\end{array}$ \\
\hline 4 & $\begin{array}{l}31.45 \\
19.53\end{array}$ & 49.02 & $\begin{array}{l}1.914 \\
1.681\end{array}$ \\
\hline 5 & $\begin{array}{l}29.07 \\
17.09 \\
\end{array}$ & 53.84 & $\begin{array}{l}3.021 \\
1.253 \\
\end{array}$ \\
\hline
\end{tabular}

Figure (4): shows the rate of copolymerization of $\mathrm{M}_{1}, \mathrm{M}_{2}$ for different composition, the rate of copolymerization increases with increase the percentage ( $\%$ ) of AA, $\left(r_{2}>r_{1}\right)$, because the monomer AA is more reactive than the monomer AM in the copolymerization of (AA/AM) system.

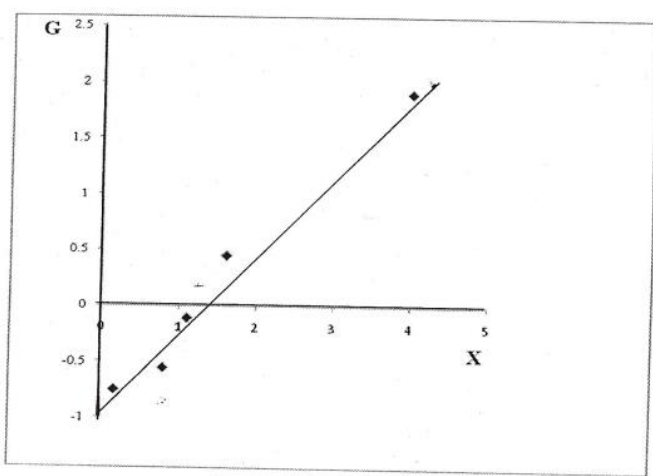

Fig. (1): Determination of the reactivity ratios for $\mathrm{AM} / \mathrm{AA}$ system at $70^{\circ} \mathrm{C}$ Finemon - Ross plot . where $G=(F-1) f / F \quad, X=\mathbf{f}^{2} / F$

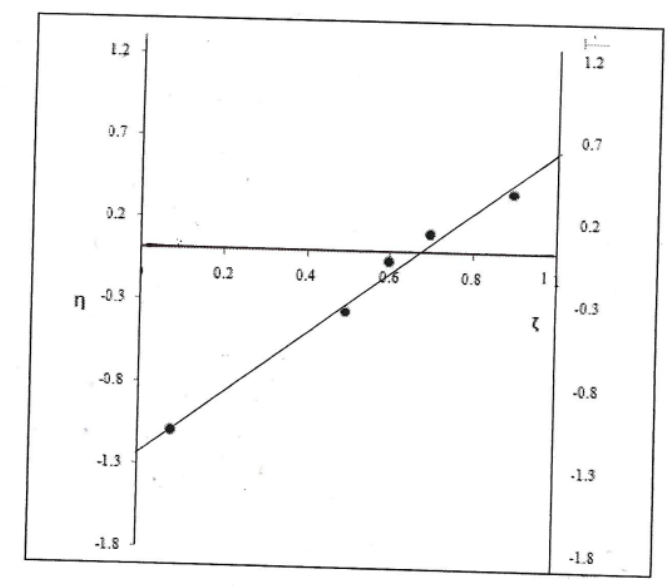

Fig.(2): Determination of the reactivity ratios for $\mathrm{AM} / \mathrm{AA}$ system at via Kelen - Tudos plot. Where $\boldsymbol{\eta}=\mathbf{G} /(\boldsymbol{\alpha}+\mathbf{X}), \zeta=\mathbf{X} /(\boldsymbol{\alpha}+\mathbf{X}), \boldsymbol{\alpha}$ $=\left(X_{\text {min. }} \times X_{\text {max. }}\right)^{1 / 2}$.

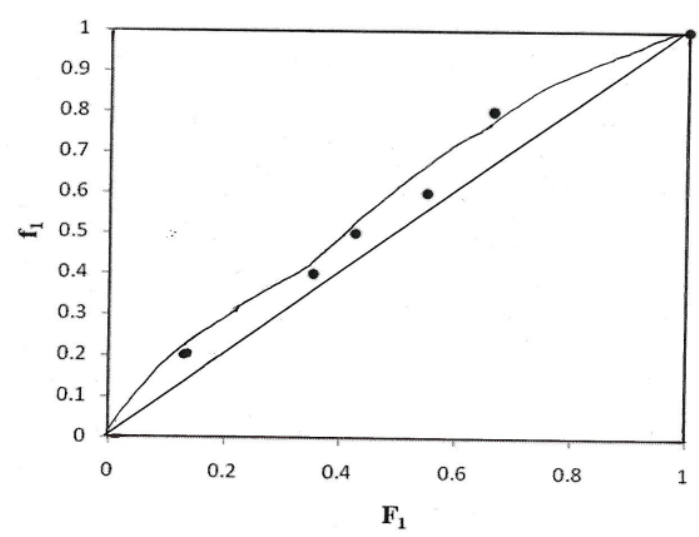

Fig. (3): Coploymer composition curves. Experimental data are represented by (•) - AM/AA System.

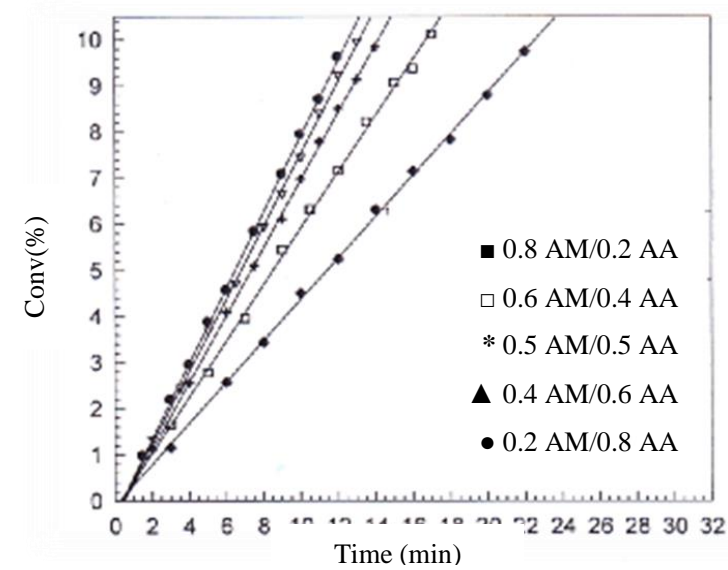

Fig. (4): Time - conversion curves for radical copolymerization of AM/AA system 


\section{References :}

1- Muhammad,H.2010.A kinetic study of Acrylamide/Acrylic acid copolymerization, Applied science, Chemical Engineering, 43:21372145.

2- Ma,L. Wang,C.and Yang, W. 2009. Dispersion polymerization of Acrylamide and acrylic acid in aqueous media, Advanced Materials Research, 87.( 88): 233-238.

3- Jianjun,X. Jifu,L. and Sai,L. 2007. Absorbency and adsorption of poly(acrylic acid-Co-acrylamide), Chemistry Industry and Engineering, 261:121-129.

4- Goa,B. and Wu. Y.C. 2008. poly (acrylamid-Co-acrylicacid)-poly (vinylpyrrolidone) polymerblends prepared by dispersion polymerization, Macromolecular science, part B, 47: 544-554.

5- Echeverria,C. Pezand,D.L . and Mijangos.C.2009.UCST Responsive microgels of poly(acrylamid-acrylic acid) copolymer:structure and viscoelastic properties, Macromolecules, 42:9118-9123.

6- Vinu,R. and Madras. G.2009. photocatalytic degradation of poly (acrylamide-Co-acrylic acid), Physical chemistry, 113: 1648516494.

7- Liaw,D.J. Huang,C.C. Sang, H.C. and Wu.P.L.2002.photophysical and aqueous solution properties of the imosensitive anionic potassium-2terpolymer, polymer Science, 41: 6123-6133.

8- Chiantore,O. Trossarelli, L. and Lazzari.M.2000.photo oxidative degradation of acrylic and methacrylic polymer, Polymer Science, 41:1657-1668.

9- Fineman, M. and Ross. S.D. 1950.Linear method for determining monomer reactivity ratios, Polymer Science, 5: 259-265.

10- Kelen ,T. and Tudos, F. Turcsanyi.1980.A new improved linear graphical method for determing copolymerization reactivity ratios, B. Polymer Bull., 2:71-76.

11- Yamada,B. Yoshioka,M. and Otsu,T.1984.Determination of absolute rate constants for free radical polymerization of ethyl fluoro acrylate.Polymer Science, Polymer Chemistry Ed. 22: 23812393.

12- Salazer,L.C. and Mcormick. C.L. 1989. synthesis and characterization of poly acrylamideCo-acrylic acid hydrogel containing silver, Polymer prep.30: 344-348.

13- Igarashi,S.1963.Thermogravim etric analysis of styrene acrylonitrile copolymer, Polymer Science, Polymer-Leit., Ed.,1:359.

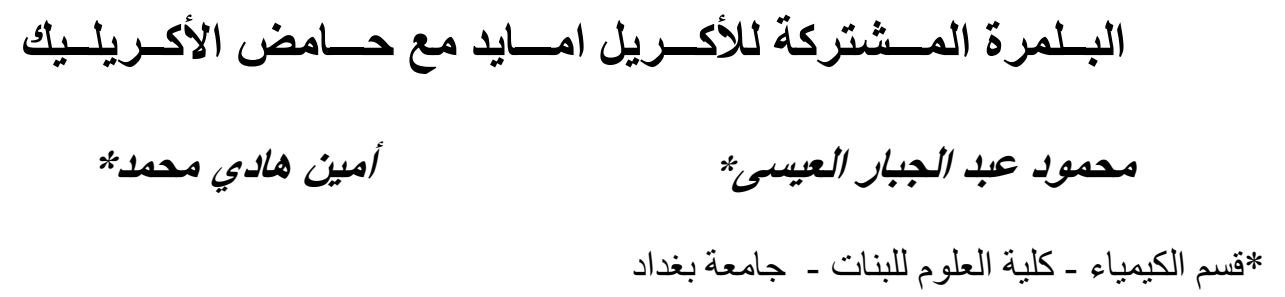

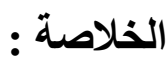

تمت البلمرة المشتركة لمونومير الاكريل امايد مع حامض الاكريليك في مذيب البنزين الجاف بوجود البادئ

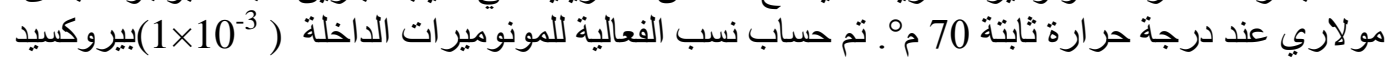
البنزويل Fineman and Ross Method باستخدام طريقتين: فاينمان وروس

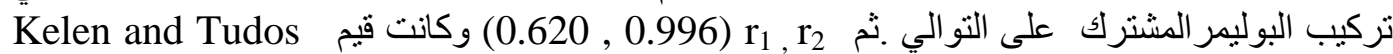
Method ان فعالية حامض الاكريليك اكبر من فعالية الاكريل امايد في نظام البلمرة المشتركة . 